\title{
Pura Vida with a Purpose: \\ Energizing Engagement with Human Rights through Service-Learning
}

\section{Carolyn Bartick Ericson}

\begin{abstract}
This paper examines the effects of an international service-learning course with a strong human rights component. Human rights have social justice as an essential component and advancing both are considered core competencies in social work. International education in colleges and universities has gained in popularity as has service-learning. Research has been carried out in both these areas. However, less research has been done on the combination of the two. In this paper a course is described during which students spent three weeks in Costa Rica, the land of Pura Vida, learning about its human rights efforts, its language, getting to know its people, and providing service to some of its citizens. An analysis of student surveys and journals revealed a strengthened belief on the part of the participants that they are competent to have an impact on the world as well as having a responsibility to do so.
\end{abstract}

Keywords: International education, service-learning, international service-learning, human rights, competencies

And so the story goes, fifteen kids got the chance of a lifetime in an unknown place... and they were never, ever the same. Home may be where the heart is, but a little piece of it is missing now because it's been left in Costa Rica. Pura Vida! (Closing statement in the journal of an undergraduate social work student.)

Pura Vida! The Pure/Good Life. This common phrase in Costa Rica took on a new meaning for two groups of 15 students and their professors from the United States who came, learned, and contributed. This paper examines the effects of an international social work course with a service-learning component. The research was designed to expand the existing knowledge of the impact of international service-learning. It assesses the effect on students in several areas relevant to social work competencies, including cultural competence, engagement with diverse populations, commitment to social justice and human rights, awareness of international issues and civic engagement. This paper will also address best practices in designing international service-learning courses.

\section{REVIEW OF THE LITERATURE}

\section{Service-Learning}

Service-learning has become increasingly common across disciplines, including social work, on many college campuses. Students in Campus Compact member schools performed 366 million hours of service through organized service-learning at an estimated value of 7.4 billion dollars to communities in the 2008-2009 academic year (Campus Compact, 2009). Students at other colleges and universities provide countless

Carolyn Bartick Ericson, Ph.D., is an is an Associate Professor and Director of the Social Work Program in the Department of Sociology, Social Work and Anthropology at Christopher Newport University, Newport News, Virginia. The author would like to acknowledge Rachel Rigual Wilson, MSW, Brianna Young, MSW, and Amber Hartley, B.A. Social Work Student for their thoughtful reflections and contributions to this research. 
additional hours of service. Service-learning is a special type of course, providing unique opportunities to the learner and the recipient of the service. It is not simply a course that has a volunteer requirement. "Service-learning combines service objectives with learning objectives with the intent that the activity change both the recipient and the provider of the service. This is accomplished by combining service tasks with structured opportunities that link the task to self-reflection, self-discovery, and the acquisition and comprehension of values, skills, and knowledge content." (National Service-Learning Clearinghouse, N.D.)

Reflection is a key part of service-learning. Only through reflection can students process their experience in such a way that it is integrated into their understanding of the populations they are serving, the environment in which they live and the course curriculum. "Experiential education is inductive, beginning with raw experience that is processed through an intentional learning format and transformed into working, usable knowledge" (National Society for Experiential Education Foundations Document Committee, 1998, p. 3).

A review of studies on the effects of service-learning from 1993-2000 (Eyler, Giles, Stenson, \& Gray, 2001) found a number of positive effects of service learning on personal, social, learning and career outcomes. These included development of cultural and racial understanding and reduced stereotyped thinking. Batchelder and Root (1994) found students who participated in service-learning, compared to those who did not, evidenced greater increases in pro-social decision-making and pro-social reasoning. Ericson and Ford (2008) found that students gained an increased appreciation for the universality of childhood from students' service learning experience with children; that is, that there are common experiences that children can share despite their circumstances. This helps students relate to children of all backgrounds and facilitated connections between social policy and direct practice issues. Wakefield and Ericson (2003), in a qualitative analysis of journals of students involved in service-learning with children, found that the students developed an appreciation for the children as unique individuals who cannot be classified according to specific expectations. Closson and Nelson (2009) found that during an experience with Habitat for Humanity, students were able to learn cognitively, affectively and pragmatically. However, they did not find that the students developed an increased understanding of social justice issues, despite an increase in awareness of their middle-class privilege.

In social work education, service-learning is distinct from field practica although the two have sometimes been confused (Lemieux \& Allen, 2007). In field practica, the emphasis is on the students' development of knowledge and skills. Although learning is a core part of service-learning and it is not simply volunteerism, the service to the community and the development of the value of civic engagement are also core goals. Curriculum and service must be integrated.

More recently, Philips (2007) found publication about civic engagement "sporadic but present" (p. 7). She sees social work as a relative late-comer in using the servicelearning pedagogy, but that it is increasing in usage. She has a strong belief that the "social change for social justice" model should guide the development of service-learning 
in social work, Lemieux and Allen (2007) determined that there was insufficient rigorous evaluation research in the social work literature regarding service-learning pedagogy. It was their belief that "research on service-learning has not kept pace with the idealism that permeates much of the scholarly literature on social work community practice, as well as the advances in knowledge development in the broader service-learning field" (p. 316). They advocated for further research to strengthen the use of service-learning in social work.

The research described in this article had as its goal to determine outcomes of service-learning in an international context, including its potential to foster the development of core social work competencies. The course particularly addresses Education Policy and Accreditation Standards 2.1.4, "Engage difference and diversity in practice”, and 2.1.5, "Advance human rights and social and economic justice” (Council on Social Work Education, 2008).

\section{International Education}

Like service-learning, international education has also become increasingly popular. In the 2008-2009 academic year, 260,327 American college students studied abroad for academic credit from their home institutions, a 100\% increase in the last decade (Institute of International Education, 2010). The Commission on the Abraham Lincoln Study Abroad Program called for sending 1,000,000 students to study abroad by 2016-2017 stating that this needed to happen to further "global competence" and "national needs." (Year of Study Abroad, N.D.).

In comparison to other studies of academic programs, however, the research is less developed in the area of the effects of study abroad programs. Positive effects that have been found include language acquisition, personal and professional development and positive academic outcomes (Dolby, 2007). Ford and Ericson (2003) found that social work students, participating in an international experience in the Netherlands, showed changes in self-perceptions that were still present six months later, most notably for students who had never left the country before. All student participants were more aware of global issues and expressed interest in to travelling more for professional reasons.

According to Long (2009), "social work has been pursing and building momentum for international work based on the profession's long-standing devotion to principles of human rights and social justice” (p. 5). It is his belief that social work must think about justice from a worldwide perspective. International courses offer a special opportunity for students to do this, particularly in courses with service-learning components.

\section{International Service-Learning}

International service-learning combines international education with a servicelearning component. In their article, Going Global with Service-Learning, Hartman and Rola (2000) described their experiences with students in Mexico and found that they were "transformed as individuals and re-evaluated themselves as persons" (p.21). These students often study second languages, become involved in additional international service-learning courses, and maintain contact with host families. Kiely and Nielsen 
(2002/2003) emphasized the importance of partnerships, noting that recognition of partners' needs supports the creation of a program with service-learning course objectives for mutual benefit. As a result, students were able to achieve, among other things, intercultural competence, language skills, and an appreciation of difference.

Many studies of international service-learning are in the form of case studies. Monard-Weissman (2003) found that students in Ecuador became more sensitive to the needs of citizens in other parts of the world and were able to examine their own roles as citizens of the world, developing an enhanced sense of social justice. Using a longitudinal case study design, Kiely (2005) concluded that a transformational learning experience occurred for students performing service-learning in Nicaragua. Students experienced transformative learning in one or more of the following areas: political, moral, intellectual, cultural, personal, and spiritual. Students were less likely to adapt to the status quo, reflecting a greater sense of social justice.

Gorka and Niesenbaum (2001) stress the importance of interdisciplinary courses that support language immersion in other countries as a way of showing the relevance of learning a foreign language to non-language majors. They also emphasize the importance of a partnership with organizations in other countries. This partnership allows for opportunities for students beyond traditional tourism or study abroad programs without a partnership. International service-learning may also generate profound questions such as: Why are so many people poor? Why is there so much inequality and injustice? (Grusky, 2000). Service-learning provides the opportunity for "teachable" moments, noting that the real power of international service-learning is at the "critical juncture where experience meets study, critical analysis, and reflection” (p.861). She cautions, however, against exploiting poor nations to provide a life-enriching experience for students. Consistent with this, Porter and Monard (2001) emphasize reciprocity (or the Bolivian term "Ayni”) as imperative. They describe several aspects of Ayni based on their experience with students building a school in Bolivia, including that "service programs must be based upon a foundation of genuine need as expressed by the recipients" and "Ayni cycles involve a different conception of time and place, and place participants in an ongoing relationship that extends across both generation and geography" (p.8). Monard-Weissman (2003) also found that students developed a deeper sense of social justice in her case study of an international service-learning experience in Ecuador.

In addition to promoting an understanding of human rights, international service learning has also found to impact students' cultural competency. Through an analysis of reflective journals of graduate students performing service in Peru, Porter (2003) found that students engaged with others, not only with the head but with the heart. As they constructed a new Head Start-like preschool building along with local residents, students were able to fulfill Wegner's charge that "educational design must engage learning communities in activities that have consequences beyond their boundaries, so that students may learn what it takes to become effective in the world” (Wegner, 1998, p. 274 as cited in Porter, p. 61).

Boyle, Nackerud and Kilpatrick (1999) determined that, following a service-learning experience in Mexico, students showed an increase in cultural competence. They stress 
the need for preparing students to interact with the Hispanic/Latino population because of the ongoing increase in this population in the U.S. This international experience was designed, in part, to support the students' competence in working with the Hispanic/Latino population.

Although not completely consistent, research in service-learning shows positive outcomes in the development of an increased understanding of human rights and commitment to social justice. International service-learning is not unique in its ability to do this but provides an opportunity for students to immerse themselves in another culture and understand the need for a universality of human rights. A social work international service-learning course has definite potential to build competencies around diversity and difference as well as human rights and social justice. This research was designed to determine the effectiveness of one international service-learning course at accomplishing those things.

\section{METHODOLOGY}

\section{The Course}

This research was carried out during two three-week international courses with service-learning components in Costa Rica. The implementation of the two courses took place two years apart. The social work course title was Human Rights: The Costa Rican Perspective. All goals of the course reflect The Educational Policies and Accreditations Standards (EPAS) (Council on Social Work Education, 2008). As noted earlier, the course particularly addresses Standards 2.1.4, "Engage difference and diversity in practice”, and 2.1.5, “Advance human rights and social and economic justice”. The goals of the course were for the students to:

1. Understand the concept of human rights.

2. Understand the historical development of global human rights.

3. Understand the role of the United Nations in working towards the protection of human rights.

4. Understand what governmental and non-governmental organizations are doing to advance human rights.

5. Have an understanding of the rights of women, minorities, indigenous peoples, children and other vulnerable populations.

6. Develop self-awareness with respect to one's own perception of human rights.

7. Understand efforts that have been put forth in Costa Rica in the service of human rights.

8. Understand the importance of language within a culture.

9. Increase facility in the Spanish language at the appropriate level.

10. Understand cultural norms and traditions within Costa Rican society. 
11. Understand the culture that the immigrant Central American population brings to the U.S.

12. Understand the relationship of the U.S. to other countries in the process of enhancement of global human rights.

The international experience was designed to quickly immerse the students in the culture and life of Costa Rica and was developed in partnership with a language school. During their language education, students were housed with Costa Rican "Tico" (local) families with whom they lived for two weeks. Most of the family members spoke little or no English which allowed for a full immersion experience. Upon arrival in Costa Rica, students were tested for placement in Spanish classes and began those classes the next morning. The students had 24 hours of small group instruction. Although the course was not intended to be a Spanish language course, language is a critical part of a country's culture and was intended to support the development of students' cultural competence.

A total of three weeks was spent in Costa Rica. During the first two weeks, the students stayed with their Tico families, studied Spanish, visited social service agencies and area neighborhoods and met with Costa Rican university students and faculty. The second group to participate in this course also developed a program for older adults in a day treatment center and did a beach cleanup. The third week was spent at a residential center for 80 children in the mountains about an hour outside of San Jose, the capital city of Costa Rica. The center provides services for children and adolescents who have little access to social services and few economic resources or opportunities for their healthy development. The children at the center were temporarily living apart from their families as a result of abuse, neglect, or extreme poverty and ranged in age from preschoolers to teenagers. Students shared one of the many houses on the grounds of the center and were assigned to have meals with the children as well as interact with them after dinner. While the children were in school during the day, the students performed several service activities at the request of the partner staff of the center. This insured that the needs of the partner organization were clearly met. Service activities included painting the interior of a building which was to be used as an art center, painting the playground equipment, preparing lunch for the children and staff, painting of houses and reconstruction of one of the houses. Two students requested the opportunity to volunteer in the school which was eagerly accepted. In fact, their second day in the school, they were substitute teachers for the first grade! This occurred despite their limited Spanish ability and lack of prior teaching experience.

Prior to leaving for Costa Rica, all students were asked if they would be willing to participate in a research study designed to assess the impact of an international servicelearning experience. The proposed research had undergone review and been approved by the university's Review Board for the Protection of Human Subjects. All students agreed to participate and signed consent forms. During the second trip, one student was unable to complete the program and therefore, did not complete her research participation and was not included in the study. The research design was a pre/post study to measure the impact of the international service learning course, with specific attention to issues of cultural 
competency and commitment to social justice, including quantitative surveys and qualitative data from student reflection journals.

\section{The Students/Participants}

The students were 29 undergraduates enrolled in a small liberal arts university in one of the Middle Atlantic States. All students were traditional age students, reflecting the demographics of the university as a whole. Six had never traveled outside the country before but the majority had and most had some prior service-learning experience. Only one had volunteer experience outside the country and this was not service-learning. A summary of participant demographics are included in Table 1.

\section{Table 1: $\quad$ Student Participant Demographics}

\begin{tabular}{lllll}
\hline Demographic & & & \\
Gender & M & F & & \\
& $3(10.3 \%)$ & $26(89.7 \%)$ & \\
Age & $18-19$ & $21-22$ & $22-23$ & \\
& $2(6.9 \%)$ & $25(86.2 .7 \%)$ & $2(6.9 \%)$ & \\
Family Income & Wealthy & Middle Class & Working-class/Poor & Other \\
& $2(6.9 \%)$ & $21(72.4 \%)$ & $(13.7 \%)$ & $2(6.9 \%)$ \\
Childhood Home & Rural & Suburban & & \\
& $5(17.2 \%)$ & $24(82.8 \%)$ & & Asian \\
Ethnic Background & Caucasian & Hispanic & Multiethnic & $3(10.3 \%)$ \\
& $23(79.3 \%)$ & $2(6.9 \%)$ & $6+$ & \\
Previous International Trips & $0-2$ & $3-5$ & $6(24.1 \%)$ & \\
& $16(55.5 \%)$ & $6(20.7 \%)$ & & \\
\hline
\end{tabular}

\section{Surveys}

Surveys were administered just before the start of the course and before departing from Costa Rica. The survey was adapted from Markus, Howard, and King (1993) and the Civic Attachments and Public Life Survey (The Walt Whitman Center, 1997) and utilized a four point Likert-type scale. Items one through sixteen were self-rating items on a list of skills and activities. Students were asked to rate themselves as compared to most people on a scale of one to four with one being not as good and four, much better. Items 17 through 24 asked the students to rate the importance of a number of items to them. Items 25 through 34 asked students to what extent they agreed or disagreed with statements. These items were chosen because they are reflective of a commitment to human rights and social justice.

\section{Journals}

The students' reflective journals provided qualitative data about their reactions and were analyzed for content themes. Students were required to use the "What? So what? 
and Now what?” model of journal reflection. They described what they observed and experienced, what they thought about it, and how they might incorporate this into their thinking about human rights as well as actions they might take as a result. This is a method favored by many experiential educators and is designed to foster reflection and promote an understanding of how the insights gained through service-learning might be applied (Campus Outreach Opportunity League, 1993).

\section{RESULTS}

Paired samples t-tests were run using SPSS 17 on all items in the survey. Of the 34 items in the survey, significant differences pre and post test were found on 21 items. Results are shown in Tables 2, 3 and 4. There was a significant statistical change in 21 items and all changes were in the direction that indicates an increased awareness and commitment to human rights on the part of the students and a sense of competence in their belief that they are able to make a change.

\section{Table 2: $\quad$ Comparison of Pre-post Measures of Self-rating of Personal} Characteristics

\begin{tabular}{|c|c|c|c|c|c|}
\hline & \multicolumn{2}{|c|}{ Pre-test } & \multicolumn{2}{|c|}{ Post-test } & \multirow[b]{2}{*}{$t$} \\
\hline & Mean & $S D$ & Mean & $S D$ & \\
\hline Respecting views of others & 3.17 & .6017 & 3.62 & .5615 & $-3.882 * * *$ \\
\hline Attentive to social issues & 2.52 & .8709 & 3.17 & .7105 & $-4.335 * * *$ \\
\hline Thinking critically & 2.65 & .7688 & 2.89 & .7243 & -1.367 \\
\hline Communicating ideas to others & 2.55 & .8274 & 3.00 & .7559 & $-2.776 * *$ \\
\hline Engaging in discussion with others & 2.79 & .8610 & 3.24 & .7862 & -2.041 \\
\hline Ability to compromise & 2.75 & .8304 & 3.03 & .6804 & -1.864 \\
\hline Listening skills & 3.03 & .6804 & 3.27 & .5914 & -1.653 \\
\hline Moral or ethical judgment & 2.96 & .8230 & 3.13 & .6394 & -1.543 \\
\hline Identification of social issues or concerns & 2.58 & .9070 & 3.14 & .7427 & $-2.911 * *$ \\
\hline Thinking about the future & 2.82 & 1.002 & 3.20 & .9775 & $-2.807^{* *}$ \\
\hline Ability to take action & 2.82 & .8048 & 3.17 & .6584 & $-2.415^{*}$ \\
\hline Tolerant of people who are different & 3.37 & .7415 & 3.70 & .5417 & $-2.360^{*}$ \\
\hline Effective in accomplishing goals & 2.96 & .7310 & 3.24 & .6894 & $-2.117^{*}$ \\
\hline Empathetic to all points of view & 3.00 & .9258 & 3.24 & .7394 & -1.885 \\
\hline Feeling responsible for others & 3.00 & .8864 & 3.10 & .8596 & -.648 \\
\hline Knowing where to find information & 2.62 & .7752 & 2.96 & .6804 & $-2.774 * *$ \\
\hline $\mathrm{N}=29 \quad * \mathrm{p}<.05, * * \mathrm{p}<.01, * * * \mathrm{p}<.001$ & & & & & \\
\hline
\end{tabular}


Table 3: $\quad$ Comparison of Pre and Post Ratings on the Importance of Behaviors

\begin{tabular}{|c|c|c|c|c|c|}
\hline & \multicolumn{2}{|c|}{ Pre-test } & \multicolumn{2}{|c|}{ Post-test } & \multirow[b]{2}{*}{$t$} \\
\hline & Mean & $S D$ & Mean & $S D$ & \\
\hline Working toward equal opportunity for all U.S. Citizens & 3.38 & .6768 & 3.44 & .6316 & -.812 \\
\hline $\begin{array}{l}\text { Working toward equal opportunity for all citizens of } \\
\text { the world }\end{array}$ & 3.06 & .9610 & 3.48 & .6876 & $-3.550 * * *$ \\
\hline Developing a meaningful philosophy of life & 2.76 & .9876 & 3.27 & .7510 & $-4.050 * * *$ \\
\hline $\begin{array}{l}\text { Becoming involved in a program to improve } \\
\text { communities, including those in other countries }\end{array}$ & 3.24 & .6894 & 3.59 & .5680 & $-2.281 *$ \\
\hline Being very well off financially & 2.34 & .7209 & 2.37 & .7277 & -297 \\
\hline Volunteering my time helping people in need & 3.20 & .6750 & 3.59 & .5680 & $-4.137 * * *$ \\
\hline Giving $3 \%$ or more of my income to help those in need & 2.34 & .8974 & 2.83 & .9284 & $-3.136 * *$ \\
\hline $\begin{array}{l}\text { Finding a career that provides the opportunity to be } \\
\text { helpful to others or useful to societies }\end{array}$ & 3.45 & .8695 & 3.55 & .6316 & $-2.254^{*}$ \\
\hline
\end{tabular}

Table 4: $\quad$ Comparison of Pre and Post Agreement with Statements

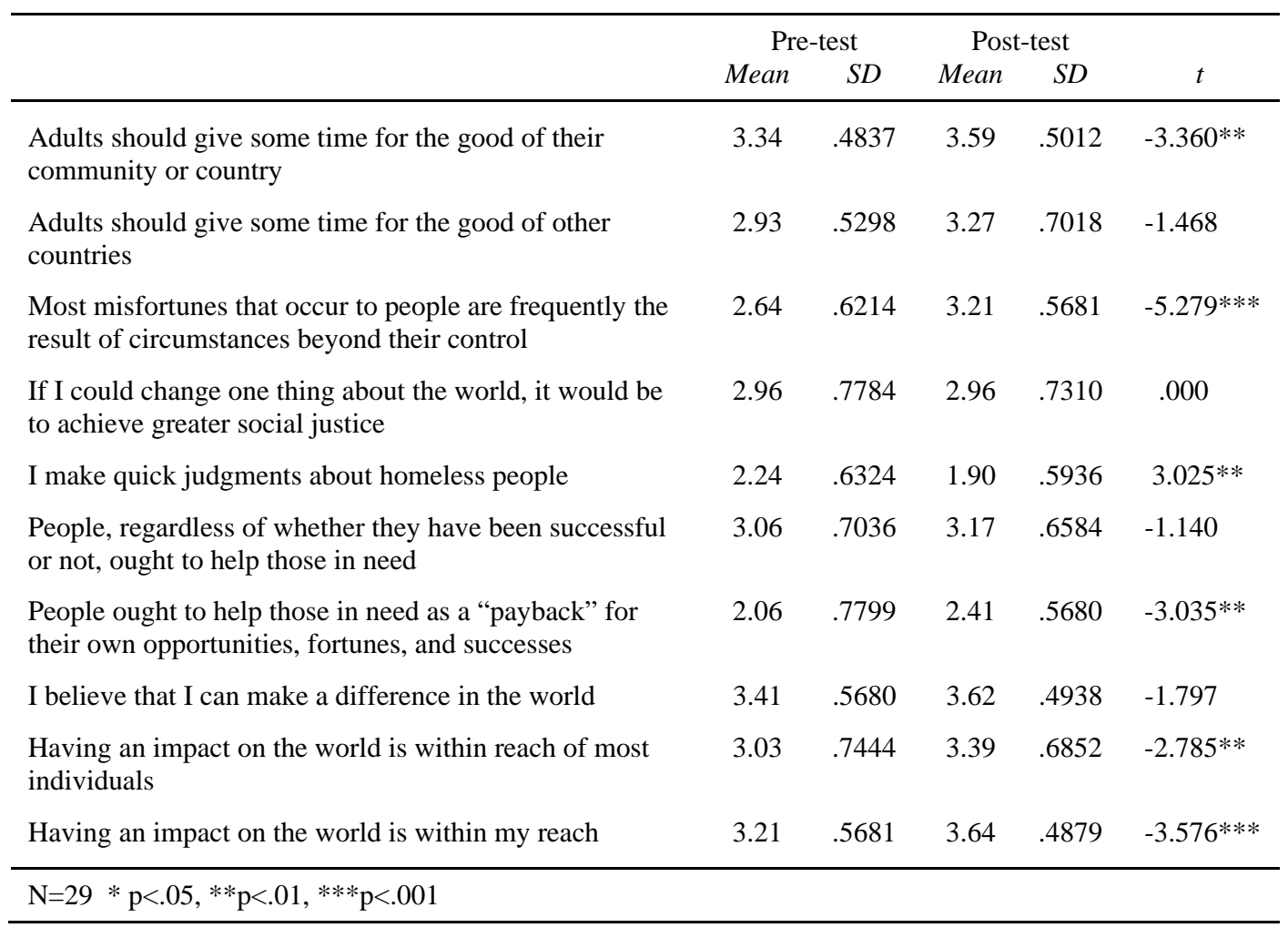




\section{Journals}

Entries in student journals were done on a daily basis and journals were collected at the end of the course. They were reviewed for recurring themes. Several themes emerged. Themes are identified and supported by student journal quotes.

\section{Human Rights}

Human Rights, the major focus of the course, emerged in all journals. Students were able to think about the importance of Human Rights in their own country as well as others.

We also talked about human rights in the U.S. and how social workers should realize the importance of human rights. We talk about cultural relations and how it is difficult to decide on basic human rights standards for the whole world when culture varies so greatly. I think it is impossible to hold everyone to the same standards, especially American standards. Who are we to judge other countries and their problems when we haven't even accepted the UN Convention? America really needs to accept those conventions and be a good example for other countries.

\section{Language}

Language emerged, without exception, as an important ingredient of the course. This supports the assertion by Gorka and Niesenbaum (2001) that it is important to engage non foreign-language majors in immersion experiences to help them see the importance of learning a foreign language (only one of the participants was a Spanish major). Language competency is not essential for cultural competence but this experience demonstrated how it may contribute to it in very important ways. The students felt more empowered and competent as a result of their increased language ability and also developed an understanding of the difficulty a new language poses for people entering a new country.

Today in class we were able to learn important expressions such as hello and thank you. These phrases will help me in getting around when I am talking to the locals. It actually gave me a sense of hope that I could contribute in the conversations that my fellow student and host family are engaged in every minute. When I am in a position where I don't understand the language it makes me believe that Americans in general go to countries expecting everyone to speak English. Not only internationally but also in the United States. having expectations of others is placing judgment and assumptions that can hinder the services when working with a client who is racially different or even speaks only one language.

\section{Existence of poverty}

Students made frequent observations of the poverty within which many citizens have to live. Rather than turn their eyes away from it, they took it in, processed it, and wanted to share their experiences with others. 
After viewing downtown and all of the historical landmarks, the professor from the University of Costa Rica took us into the slums. This was a very sad part of the day for me. There was trash all in the streets....The houses of the people who lived in the slums were made of boxes and dirt. Their ceilings consisted of old boxes and metal that they could find laying around. What hit me the hardest was to see all of the school children in the streets. No one deserves to live like that. ...It is one thing to see stuff like that on TV, but when you see it with your own eyes it is totally different. I wish that everyone could have seen what we saw today.

\section{Personal growth}

Many of the students were aware of personal growth while on the trip. They were thoughtful about changes taking place within themselves and the impact it would have on them in the future.

I am truly growing as a person on this trip. The way I view life, people, and happiness has all changed for the better. I no longer take for granted the life that my parents have provided for me. I am so grateful!

All I can really say is that I am changed due to this experience....I shouldn't limit myself to only working in the U.S., especially when so many people in other countries need help. Overall, this three-week adventure in Costa Rica has made me tremendously more culturally competent with Costa Ricans. I can't wait to learn more about other cultures!

\section{Needs of Children}

Students were very affected by the children with whom they interacted. They attempted to understand the children's behavior within the context of their experiences.

We got assigned to the house of Jessie which was a house of all boys aged from probably nine to twelve years old. From the second we met them I was receiving huge hugs and high fives and acceptance without even having to prove myself which is something I haven't ever really seen.....I just don't understand their attachment to us but I guess that's what they really need.

\section{DISCUSSION}

Students participating in this international service-learning course evidenced important gains which contributed to their development of social work competencies. Although the implications of this study are limited by the fact that there was no control group, it seems unlikely that students who spent their first three weeks of the summer pursuing more typical summer experiences or even those who studied similar content without the international service-learning experience would show similar gains. It is important that the students were immersed in the culture and language of Costa Rica before they began their service experience. By the time they entered the service sites, the students had completed basic Spanish instruction, had visited some of the neighborhoods 
from which the children in the Center came, and had learned about social services in the country. They had also learned about and examined the human rights approach of the government and citizens of the country. The combination of the course content with cultural immersion and service activities contributed to the overall gains and contributions made during this experience.

The survey results indicated that students believed more strongly that they could have an impact on the world and showed an increased sense of responsibility to do so. The change in their sense of their own capacity, as well as the capacity of all people, to make a difference was empowering to them. Rather than become overwhelmed by what they experienced, they developed an increase sense of their own competence to help to improve the lives of others. Further evidence of these changes was visible when they began a university-approved club to support the Children's center in Costa Rica where they had done a week of service. They are developing fund-raising activities to buy new playground equipment that they observed to be old and unsafe. This club will recruit members from the general university population and will go on after the trip participants graduate.

In addition to the changes in their competency around social justice, they also demonstrated increases in competencies around dealing with diversity and difference. They believed that they became more tolerant and less judgmental. If students are to develop a sense of how to support the rights of other, they cannot be judgmental of others.

The importance of volunteering and making financial contributions, another form of action to promote social justice, was also strengthened. In fact, some of the students chose to become continuing sponsors of children in the center which is often difficult to manage on a student budget.

In addition to the survey findings, the student journals also demonstrated the students 'sense of the importance of human rights overall, particularly of children, and, for those who were in the group that went to the older adult center, of that population as well. They recognized the importance of language to a country's culture and a need to learn how to communicate in that language to be most effective in serving others. Students evidenced in both journals and in the surveys development which will enhance their ability to serve other world populations in the future. There was growth in all students even though most were social work majors who came into the service experience with a pre-existing strong commitment to others.

This was a small sample involving one course and the results cannot be generalized. However, it supports the belief that service-learning has tremendous potential to help students recognize the value of service as well as to enhance their learning in many areas, particularly human rights and social justice and diversity and difference, in direct support of the related EPAS competencies (CSWE, 2008). International experiences have the potential to broaden student thinking in ways that are hard to replicate domestically. Combining the two has even greater potential to strengthen the competencies identified above. 
However, there are certainly challenges to maximizing the opportunity for learning in international service-learning courses. Each course must be designed to prepare students adequately for the experience, incorporate reflection, and have a strong academic component. Several meetings were held with the students prior to the inception of the course to familiarize the students with Costa Rica, its people, its culture, as well as the behavioral and academic expectations of the service-learning course. Students may see a summer international experience as a vacation and it is not. In this course, students were involved with course content at least 8 hours a day, however, weekends were left for recreation to allow students to take advantage of the many opportunities available. In addition to journaling, students were required to do an oral presentation on human rights to the group and were required to write a paper after completion of the trip comparing and contrasting Costa Rican and U.S. policies with human rights implications. A continued examination of the effects of these experiences and the best way to design courses which provide them is important to social work.

In addition, this type of course is not without its challenges for the educator. There is a tremendous amount of preparation time. Practical matters such as housing, meals, flights and in-country transportation have to be planned. Universities increasingly have protocols for issues of safety and legal liability that must be followed. It is very important for the instructor to have familiarity with the country, have visited the country previously, and ideally to have had the opportunity to go there ahead of time for planning purposes. A strong relationship with the service-learning site and sensitivity to their needs of the organization is critical. The primary instructor for the course had a pre-existing relationship with the University of Costa Rica, the Spanish school and the service site which was very helpful.

Faculty have a great deal of responsibility when taking students out of the country to an unfamiliar environment. Behavioral expectations need to be made very clear to the students and cultural sensitivity needs to be emphasized. On only one occasion was a student blatantly culturally insensitive on this trip and the language school partner (a citizen of the host country) was able to effectively challenge her misconception, but it is often the role of the instructor to facilitate recognition of cultural insensitivity on the part of the student.

The post-service evaluation completed by the partner organization staff who came into contact with the students during the service experience revealed that there were several areas that were important to them. These included coordination of efforts between the service site personnel and university faculty as well as the leadership of the faculty. The work which the partner organization requested was accomplished and relationships developed between the program participants, site personnel and older adult children to the benefit of all.

The importance of respect for the host institution and coordination with them both before and during the experience was clear. It seems that the Ayni described by Porter and Monard (2001) was present, based on the partner comments and those of the students. It did not come easily, however. Much work had to take place for this to be possible. 
Benefits outweigh the challenges and careful planning and preparation for the students can result in students' enhanced cultural competence and awareness of social justice on an international scale. These qualities and skills support student achievement of the EPAS (CSWE, 2008) competencies as well as becoming citizens of the world. The world benefits also when well-prepared students who are sensitive to the culture with whom they are engaging dedicate themselves to service.

\section{References}

Batchelder, T., \& Root, S. (1994). Effects of an undergraduate program to integrate academic learning and service: cognitive, prosocial cognitive, and identity outcomes. Journal of Adolescence, 17, 341-355.

Boyle, D. P., Nackerud, L., \& Kilpatrick, A. (1999). The road less traveled: crosscultural, international experiential learning. International Social Work, 42, 201-214.

Campus Compact. (2009). 2009 Annual Survey Executive Summary. Retrieved from http://www.compact.org/wpcontent/uploads/2008/11/2009_CC_Annual_Survey_Exec Summary.pdf

Campus Opportunity Outreach League. (1993). Into the Streets campaign manual. Boston: Author.

Closson, R., \& Nelson, B. M. (2009). Teaching social justice through community engagement. International Journal for the Scholarship of Teaching and Learning, 3. Retrieved from http://academics.georgiasouthern.edu/ijsotl/

Council on Social Work Education. (2008). Educational Policy and Accreditation Standards. Retrieved from http://www.cswe.org/File.aspx?id=13780

Dolby, N. (2007). Reflections on nation: American undergraduates and education abroad. Journal of Studies on International Education, 2, 141-156.

Ericson, C. B., \& Ford, K. (2008). Energizing engagement through service-learning. Academic Exchange Quarterly, 12(3), 249-255.

Eyler, J., Giles, D., Stenson, C., \& Gray, C. (2001). At a glance: What we know about the effects of service-learning on college students, faculty, institutions and communities, 1993-2000 ( $3^{\text {rd }}$ ed.). http://www.compact.org/wpcontent/uploads/resources/downloads/aag.pdf

Ford, K., \& Ericson, C. B. (2003). An international social work exchange: What, so what, and now what? Journal of Baccalaureate Social Work, 8, 97-108.

Gorka, B., \& Niesenbaum, R. (2001). Beyond the language requirement: Interdisciplinary short-term study abroad programs in Spanish. Hispania, 84, 100-109.

Grusky, S. (2000). International service learning: A critical guide from an impassioned advocate. American Behavioral Scientist, 43(5), 858-867.

Hartman, D., \& Rola, G. (2000). Going global with service-learning. Metropolitan Universities, 11, 15-23. 
Institute of International Education. (2010). Opendoors Fast Facts 2010. Retrieved from http://www.iie.org/en/Research-and-Publications/Open-Doors/Data

Kiely, R. (2005). A transformative learning model for service-learning: A longitudinal case study. Michigan Journal of Community Service Learning, 12, 5-22.

Kiely, R., \& Nielson, D. (2002/2003). International service-learning: The importance of partnerships. Community College Journal, 3, 39-41.

Lemieux, C., \& Allen, P. (2007). Service-learning in social work education: The state of knowledge and practice conundrums. Journal of Social Work Education, 43, 325342.

Long, D. (2009). International social work education and practice. In C. Tice \& D. Long (Eds.), International social work, policy and practice (pp. 1-22). Hoboken, NJ: John Wiley \& Sons, Inc.

Maria.Abroad. (n.d.). Retrieved from www.maria.abroad.com

Markus, G., Howard, J., \& King. D. (1993). Integrating community service and classroom instruction enhances learning: Results from an experiment. Educational Evaluation and Policy Analysis, 15, 410-419.

Monard-Weissman, K. (2003). Fostering a sense of justice through international servicelearning. Academic Exchange Quarterly, 7(2), 164-172.

National Service-Learning Clearinghouse. (n.d.). Retrieved from www.servicelearning.org

National Society for Experiential Education Foundations Document Committee. (1998). Foundations of experiential education. Raleigh, NC: National Society for Experiential Education.

Philips, A. (2007). Social work and service-learning: A natural but tenuous connection. In M. Nadel, V. Majewski, \& M. Sullivan-Cosetti (Eds.), Social work and servicelearning: Partnerships for social change (pp. 3-20). Lanham, MD: Roman \& Littlefield Publishers, Inc.

Porter, M., \& Monard, K. (2001). Ayni in the global village: Building relationships of reciprocity through international service-learning. Michigan Journal of Community Service-Learning, 8, 5-17.

Porter, M. (2003). Forging L.I.N.C.S. among educators: The role of international servicelearning in fostering a community of practice. Teacher Education Quarterly, 30(2), 52-67.

The Walt Whitman Center. (1997). Civic attachments and public life survey. New Brunswick, NJ: Rutgers, The State University of New Jersey.

Wakefield, M. O., \& Ericson, C. B. (2003). Pathways to intergenerational understanding. Academic Exchange, 7(2), 203-330.

Year of Study Abroad. (n.d.). Retrieved from www.yearofstudyabroad.com 


\section{Author note:}

Direct correspondence to: Carolyn Bartick Ericson, Ph.D., Associate Professor and Director of the Social Work Program, Department of Sociology, Social Work and Anthropology, Christopher Newport University, 1 University Place, Newport News, VA 23606. Email: carolyn.ericson@cnu.edu 